\title{
Jornalismo e Inteligência Artificial: Tendências nas Pesquisas Brasileiras entre 2010 e 2020
}

\section{Fabia Cristiane loscote}

Doutoranda em Comunicação e

Formações Socioculturais pelo Programa de Pós-Graduação em Comunicação da Universidade Federal do Paraná (UFPR). E-mail: jornalistafabiaioscote@gmail.com
Resumo: Este trabalho apresenta um estado da arte no que se refere às pesquisas brasileiras que abordam o tema do jornalismo e a inteligência artificial (IA). Trata-se de um levantamento de artigos publicados em periódicos brasileiros e nos congressos nacionais SBPJor, Compós e Intercom Nacional entre 2010 e 2020 cujo objetivo é compreender as principais discussões nos trabalhos. O corpus é composto por 19 artigos publicados em periódicos e 27 artigos publicados em congressos. Os procedimentos metodológicos adotados são a revisão bibliográfica e uma análise quantitativa com um conjunto de diferentes softwares. A partir da leitura dos títulos, resumos e palavras-chave, foi realizada uma análise qualitativa, de caráter inferencial, de coocorrências e conexões entre palavras com o software Iramuteq. Os resultados evidenciam que os periódicos discutem ferramentas e pesquisas aplicadas com ênfase nos dados e notícias, enquanto nos congressos prevalece a discussão do algoritmo e as implicações para o trabalho do jornalista.

Palavras-chave: algoritmos, automatizado, dados, notícias, estado da arte.

Periodismo e Inteligencia Artificial: Tendencias de estudios Brasileños entre 2010 y 2020

Resumen: Este trabajo presenta un estado del arte con respecto a los estudios brasileños que abordan el tema del Periodismo y la inteligencia artificial (IA). Se realizó una encuesta de los artículos publicados en revistas brasileñas y en los congresos nacionales SBPJor, Compós e Intercom Nacional entre 2010 y 2020, con el objetivo de comprender las principales discusiones en los trabajos. El corpus consta de 19 artículos publicados en revistas y 27 en congresos. Se realizó como procedimiento metodológico una revisión de la literatura y un análisis cuantitativo con un conjunto de softwares. Desde la lectura de títulos, resúmenes y palabras clave, se realizó un análisis cualitativo, inferencial, por coocurrencia y conexiones entre palabras con el software Iramuteq. Los resultados muestran que las publicaciones discuten sobre herramientas e investigación aplicada con énfasis en datos y noticias, mientras que en los congresos prevalecen la discusión sobre el algoritmo y las implicaciones para el trabajo del periodista.

Palabras clave: algoritmos, automatizado, datos, noticias, estado del arte.

Journalism and Artificial Intelligence: Trends in Brazilian Research between 2010 and 2020

Abstract: This work presents a state of the art regarding Brazilian research that addresses the topic of journalism and artificial intelligence (A.I.). This is a survey of articles published in Brazilian journals and in national congresses SBPJor, Compós, and Intercom Nacional between 2010 and 2020 whose objective is to understand the main discussions in these works. The corpus consists of 19 articles published in journals and 27 articles published in congresses. The methodological procedures adopted are a literature review and a quantitative analysis with a set of different softwares. From reading the titles, abstracts, and keywords, we performed a qualitative inferential analysis, by co-occurrence and connections between words with the Iramuteq software. The results show that periodicals discuss tools and applied research with an emphasis on data and news, whereas in congresses prevails a discussion of the algorithm and the implications for the journalist's work.

Keywords: algorithms, automated, data, news, state of the art. 


\section{Introdução}

A Inteligência Artificial (IA), com raízes na Ciência da Computação e presente em nossa sociedade desde a década de 1950, apresenta avanços mediante a junção de conhecimentos de diferentes áreas que fornecem inovações tecnológicas para o corpo social. Pesquisas que envolvem simultaneamente conhecimentos da Computação, da Matemática, da Estatística, da Biologia, da Linguística, da Psicologia, da Neurociência, entre outras áreas, nos colocam em cenários inovadores com carros autônomos, assistentes virtuais, smarthouses, sistemas de recomendações etc., sem considerar, de maneira mais aprofundada, as inovações aplicadas na área da saúde. Desse modo, os avanços nas pesquisas que contemplam o uso da IA vêm transformando o mundo.

Ao passo que a IA é planejada para executar tarefas e auxiliar na tomada de decisões, os algoritmos - que são as bases das operações de um software- reorganizam a informação atuando, inclusive, como mediadores em nosso cotidiano. Tais inovações despertam inquietações e, ao mesmo tempo que, por vezes, fascinam, também ocasionam dilemas. Em síntese, as discussões em torno da era da governança algorítmica (Bucher, 2012; Gillespie, Boczkowski, \& Foot, 2014; Martin, 2019) colocam em xeque responsabilidades, ética e profissões. Qual é, então, o futuro da humanidade diante de tanta inovação tecnológica?

Sob a ótica do jornalismo, as mudanças relacionadas à tecnologia estão em debate há algumas décadas e propõem que o jornalista que quiser continuar no ofício precisa estar em constante atualização (Lima \& Caetano, 2015). Questões mais recentes também vêm sendo estudadas, como as redes sociais digitais, a produção de notícias com argumentação relacionada ao uso da IA e a adoção de algoritmos editoriais (Marconi, 2020). O expressivo volume de dados disponibilizado em rede que caracteriza o big data e o fenômeno da dataficação-num movimento histórico de numerização progressiva do mundo (Mersch, 2019; Sadin, 2015; van Dijck, 2014) - servem, sobretudo, como base para questionamentos relacionados ao ofício do jornalista e a rotina da produção jornalística. Seria o fim do jornalista humano nas redações?

Diante dessa breve contextualização, este trabalho propõe, por meio de um estado da arte, verificar como o jornalismo vem sendo estudado por pesquisadores brasileiros a partir de artigos apresentados em congressos e publicações em periódicos nacionais da área de Comunicação no contexto da IA. O recorte temporal engloba as produções acadêmicas de 2010 a 2020 e o corpus de análise é composto por 27 trabalhos publicados nos anais de congressos nacionais $(n=27)$ e 19 artigos publicados em periódicos brasileiros $(n=19)$. O objetivo geral é compreender as principais temáticas que envolvem a interface de pesquisas acadêmicas entre jornalismo e IA. Os objetivos específicos consistem no levantamento quantitativo dos artigos e na análise dos trabalhos em abordagem qualitativa a partir de títulos, resumos e palavras-chave. Os procedimentos metodológicos adotados são a revisão bibliográfica e uma análise quantitativa com o apoio de um conjunto de diferentes ferramentas, utilizadas desde a etapa de coleta e de visualização até a análise dos dados, e operações estatísticas simples com os softwares Mendeley, Excel, RAWGraphs e a linguagem de programação Python, com script adaptado dos trabalhos do Laboratório de Convergência de Mídias da Universidade Federal do Maranhão (LABCOM-UFMA). Também foi utilizada a análise de similitude (Marchand \& Ratinaud, 2012) com o software Iramuteq para uma ênfase qualitativa.

A escolha pelo termo Inteligência Artificial, em detrimento de expressões como automação ou robô, justifica-se na amplitude do conceito. O termo Inteligência Artificial foi cunhado em 1955 pelo cientista da computação John McCarthy, que associou a linguagem e a inteligência ao raciocínio, ao aprendizado e à resolução de problemas. Portanto, a IA é uma área da Ciência da Computação que contempla procedimentos e métodos, interessa a diferentes campos e propicia um sistema que envolve a simbiose humano-máquina, conexões e interações (Kaufman, 2018; Lima Junior, 2019). É possível descrever, ainda, a IA como sistemas computacionais que emulam o raciocínio lógico humano. Estes sistemas, ditos inteligentes, são uma forma de automação. Contudo, depreende-se que a utilização da terminologia automação 
delimita a perspectiva de estudos aos processos que não necessariamente são dotados de inteligência. Nesse sentido, a expressão Inteligência Artificial para o contexto jornalístico abarca as possibilidades de automação dos processos ou das rotinas produtivas (Diakopoulos, 2019; Marconi, 2020), os robôs - sejam eles softwares representados por chatbots ou na figura humanóide (Barcelos, 2019) - e, numa esfera comunicacional, as interações e mediações (Manovich, 2012; Winques, 2020).

Destaca-se que outras investigações semelhantes já foram desenvolvidas acerca das transformações na área, como o jornalismo digital, numa busca pelos autores e autoras do tema no Brasil no período entre 1996 e 2006 (Quadros, Mielkniczuk, \& Barbosa, 2006). Este estudo identificou seis pesquisadores de universidades públicas com trabalhos relacionados ao jornalismo no ambiente digital que articulavam conceitos, práticas, circulação das notícias, principais desafios, identidade do jornalista, ética e o futuro. No âmbito internacional, pesquisas recentes também realizaram um levantamento por meio da revisão sistemática da produção científica sobre jornalismo e IA entre 2008 e 2019 (Rubio \& Ruiz, 2021). No levantamento ( $n=209$ ), as publicações de pesquisadores norte-americanos são a maioria (33\%), seguidas pelas publicações sul-coreanas (9,1\%). Os pesquisadores brasileiros representam 2,3\% da amostra. Essa constatação permite questionar: o que estudam os pesquisadores brasileiros?

Em um cenário digitalmente globalizado, em que vocábulos como big data, algoritmos, machine learning, deep learning, processamento de linguagem natural (PLN), redes neurais artificiais, entre outros, são cada vez mais recorrentes na sociedade, em especial a partir de 2010 , justifica-se o impulso para a investigação sobre as tendências nas pesquisas brasileiras que articulam a temática entre jornalismo e IA. Nesse sentido, tendo em vista as indicações dos estudos citados, espera-se identificar abordagens tratadas a partir de 2010 no panorama brasileiro que possam evidenciar mudanças ou continuidades. Ademais, esse estado da arte é parte dos trabalhos de uma tese de doutorado em andamento no Programa de PósGraduação em Comunicação da Universidade Federal do Paraná (PPGCOM-UFPR).

Essa pesquisa está organizada de forma a apresentar, na introdução, o problema, os objetivos e a justificativa para depois abordar os procedimentos metodológicos, fazer uma breve contextualização teórica sobre a IA no campo jornalístico, apontar os resultados e as discussões e, por fim, apresentar as considerações finais.

\section{Procedimentos metodológicos}

Os procedimentos metodológicos desta pesquisa foram realizados em duas etapas: 1. levantamento de trabalhos nos congressos e periódicos brasileiros entre os anos de 2010 e 2020 e organização dos dados encontrados com apoio dos softwares Mendeley e Excel; 2. análise do material encontrado, que foi dividido em dois corpora, denominados congressos e periódicos, em uma abordagem quantitativa e qualitativa. Para tanto, foram realizadas a leitura dos títulos, resumos e palavras-chave dos trabalhos encontrados e operações estatísticas simples no Excel, bem como foi utilizada a ferramenta RAWGraphs, a linguagem de programação Python para visualização e o software Iramuteq, a partir da análise de similitude (Marchand \& Ratinaud, 2012) para uma abordagem inferencial das coocorrências e conexões entre as palavras, caracterizando a ênfase qualitativa do corpus. Estes softwares foram escolhidos por serem gratuitos e por facilitarem a organização e a visualização dos dados. Já a linguagem de programação Python permite fazer ajustes necessários nos scripts considerando os objetivos da pesquisa. A escolha pelo Iramuteq e a análise de similitude, em detrimento de outros métodos, como a análise de conteúdo (Bardin, 2016), tem inspiração na proposta metodológica de Cervi (2018). Pretende-se obter a menor interferência de subjetividades por parte do investigador no que antecede os resultados e, ao mesmo tempo, aumentar a possibilidade de replicar a técnica.

O primeiro passo da etapa inicial foi incluir trabalhos ao recorte temporal que envolvessem a temática entre jornalismo e IA em 2020, uma vez que esse levantamento já havia sido realizado em 2020, mas contemplando apenas pesquisas entre 2010 e 2019 (loscote, 2020). Essa complementação foi realizada em 8 de maio de 2021 nos 
anais disponíveis nos sites de três congressos nacionais da área de Comunicação e jornalismo: Associação Brasileira de Pesquisadores em Jornalismo (SBPJor), Associação Nacional dos Programas de Pós-Graduação em Comunicação (Compós) e Congresso Brasileiro de Ciências da Comunicação (Intercom).

Para a busca, foram escolhidas sete palavras principais (Quadro 1) que se referem ao contexto da IA, ponderando sobre aquelas que poderiam estar relacionadas ao jornalismo diante do exposto na literatura (Anderson, 2012; Diakopoulos, 2019; Latar, 2018; Lima Junior, 2011; Linden, 2018; Marconi, 2020; Napoli, 2014; Santos, 2016).

\begin{tabular}{|l|l|l|l|l|}
\hline Palavra & Abreviação & Relacionada & Tradução & Plural \\
\hline $\begin{array}{l}\text { Inteligência } \\
\text { Artificial }\end{array}$ & IA & - & $\begin{array}{l}\text { Artificial Intelligence } \\
-A l\end{array}$ & - \\
\hline $\begin{array}{l}\text { Aprendizado } \\
\text { de máquina }\end{array}$ & - & - & Machine Learning & - \\
\hline Algoritmo & - & Algorítmico(a) & Algorithm; Algorithmic & Algoritmos \\
\hline Robô & - & - & Robot; Robots & Robôs \\
\hline Automação & - & Automatizado(a) & $\begin{array}{l}\text { Automation; } \\
\text { Automated }\end{array}$ & - \\
\hline $\begin{array}{l}\text { Dados } \\
\text { estruturados }\end{array}$ & - & - & Structured Data & - \\
\hline $\begin{array}{l}\text { Dados não- } \\
\text { estruturados }\end{array}$ & - & - & Unstructured Data & - \\
\hline
\end{tabular}

Quadro 1: Palavras buscadas

Nota: adaptado de loscote (2020).

A busca por palavras nos anais disponíveis nos sites dos congressos nacionais retornou 66 trabalhos. Contudo, muitos destes artigos abordavam a IA em relação ao campo da Comunicação e, em maior amplitude, contemplavam discussões relacionadas à Publicidade e Propaganda, ao Marketing, à Comunicação Organizacional, entre outros. Desta forma, apenas 27 artigos se enquadravam no escopo desta pesquisa (Tabela 1). Esses trabalhos foram dispostos em uma planilha organizada por ano, nome do congresso, edição, título do trabalho, resumo, Instituição de Ensino Superior (IES), região, tipo de universidade - pública ou privada -, autor(es), coautor(es), palavras-chave e link do trabalho.

\begin{tabular}{l|c|c|c|c}
\hline \multirow{2}{*}{ Termos } & \multicolumn{4}{|c}{ Número de publicações } \\
\cline { 2 - 5 } & Compós & SBPJor & Intercom Nacional \\
\hline Inteligência Artificial - IA & 2 & 5 & 2 \\
\hline Aprendizado de máquina & 0 & 0 & 0 \\
\hline Algoritmo(s)/Algorítmico & 8 & 7 & 21 \\
\hline Robô(s) & 1 & 3 & 2 \\
\hline Automação/Automatizado & 0 & 0 & 2 \\
\hline Dados estruturados* & 4 & 1 & 8 \\
\hline Total em cada congresso & 15 & 16 & 35 \\
\hline Total & \multicolumn{4}{|c}{66} \\
\hline Coincidências ou falsas recuperações & \multicolumn{5}{|c}{27} \\
\hline Total & \multicolumn{5}{|c}{} \\
\hline
\end{tabular}

Tabela 1: Resultados dos termos pesquisados nos anais disponíveis nos sites dos congressos *A busca retorna dados que estão na perspectiva de base de dados.

Nota: elaborada pela autora (2021).

Os mesmos procedimentos relacionados às palavras-chave foram realizados nas buscas nos periódicos nas bases da Scopus, Web of Science, Portal de Periódicos da Coordenação de Aperfeiçoamento de Pessoal de Nível Superior (Capes) e da Scientific Electronic Library Online (SciELO), delimitando o recorte nas bases para os periódicos da área de Ciências Sociais (Tabela 2). A consulta foi feita a partir de login no portal de periódicos da Capes via Comunidade Acadêmica Federada (CAFe), que garantiu o acesso remoto às bases. Na busca em cada base foram utilizados 
os operadores booleanos AND, OR e NOT para a combinação das palavras-chave junto ao termo journalism.

\begin{tabular}{l|c|c|c|c}
\multirow{2}{*}{ Termos } & \multicolumn{5}{|c}{ Número de publicações } \\
\cline { 2 - 6 } & Scopus & $\begin{array}{c}\text { Web Of } \\
\text { Science }\end{array}$ & SciELO & $\begin{array}{l}\text { Portal } \\
\text { Capes }\end{array}$ \\
\hline Journalism AND Artificial Intelligence OR A.I. & 39 & 64 & 0 & 15 \\
\hline Journalism AND Algorithm OR Algorithmic & 114 & 385 & 4 & 3 \\
\hline Journalism AND Machine Learning & 20 & 39 & 0 & 0 \\
\hline Journalism AND Robot OR Robots & 27 & 196 & 0 & 1 \\
\hline Journalism AND Automated OR Automation & 94 & 227 & 2 & 4 \\
\hline Journalism AND Structured Data OR & 71 & 252 & 6 & 0 \\
\hline Unstructured Data & 365 & 1.163 & 12 & 23 \\
\hline Total nas bases de dados & \multicolumn{5}{|c}{1.562} \\
\hline Total & \multicolumn{5}{|c}{1.300} \\
\hline Coincidências ou falsas recuperações & \multicolumn{5}{|c}{} \\
\hline Total & \multicolumn{5}{|c}{} \\
\hline
\end{tabular}

Tabela 2: Resultados dos termos pesquisados nas bases de dados Nota: elaborada pela autora (2021).

O software Mendeley foi utilizado para organizar a coleta e as referências bibliográficas, bem como para identificar coincidências ou duplicações. Após a retirada das falsas recuperações, o corpus inicial incluía periódicos internacionais ( $n=262$ ). Na sequência, os artigos foram extraídos do Mendeley para o Excel para serem filtrados e exportados para o RAWGraphs, em que um mapa de hierarquia mostrou os periódicos com maior número de publicações entre 2010 e 2020. Entre estes periódicos estão as publicações brasileiras Brazilian Journalism Research, editada pela SBPJor, Revista FAMECOS, do PPGCOM da Pontifícia Universidade Católica do Rio Grande do Sul (PUC-RS) e Revista Observatório, do Observatório de Pesquisas Aplicadas ao Jornalismo e ao Ensino da Universidade Federal do Tocantins (OPAJE-UFT) e do Grupo de Estudos em Democracia e Gestão da Universidade Estadual Paulista "Júlio de Mesquita Filho" (GEDGS-UNESP), que, juntas, somam 19 artigos. Desta forma, o corpus para análise é composto por 27 trabalhos publicados nos anais da SBPJor, da Compós e do Intercom nacional, denominado corpus congressos $(n=27)$, e 19 artigos publicados nos periódicos Brazilian Journalism Research, Revista FAMECOS e Revista Observatório, denominado corpus periódicos $(n=19)$.

\section{Segunda etapa}

Na segunda etapa, entre 20 de maio e 30 de junho de 2021, os trabalhos foram examinados sob uma perspectiva quantitativa, com operações estatísticas simples e em abordagem qualitativa a partir de inferências das coocorrências e da conexão entre as palavras presentes nos corpora $-n=27$ e $n=19$. As palavras-chave dos corpora - congressos e periódicos - foram organizadas em duas planilhas distintas, salvas em documentos em extensão txt. e organizadas, cada qual, em uma nuvem de palavras geradas a partir da linguagem de programação Python. Esse procedimento auxiliou na obtenção de uma visão qualitativa inicial e geral do corpus.

Na planilha do Excel, foram aplicadas operações estatísticas simples para verificar o percentual de algumas questões no corpus congressos $(n=27)$ : 1 . os trabalhos são provenientes de universidades públicas ou privadas?; 2 . em qual ano está concentrada a maior produção?; 3. qual congresso reuniu o maior número de trabalhos e quais autores(as) aparecem com maior frequência? Do mesmo modo, no corpus periódicos, considerando o total de artigos encontrados $(n=262)$ e o recorte escolhido $(n=19)$, algumas estatísticas também foram verificadas, como a checagem do ano de publicação e os(as) autores(as) mais frequentes. Nesta etapa, as bases de dados foram preparadas em arquivo de extensão txt. para a utilização do software Iramuteq. 
Com as bases de dados preparadas, os resumos $n=19$ e $n=27$ foram submetidos à análise de similitude (Marchand \& Ratinaud, 2012), utilizando o software Iramuteq, a fim de fazer inferências sobre cada um dos corpora a partir da coocorrências e da conexão entre as palavras. Este tipo de análise "permite representar graficamente a estrutura de um corpus, distinguindo também as partes comuns e as especificidades das variáveis codificadas" (Marchand \& Ratinaud, 2012, pp. 687-688, tradução nossa). De acordo com Camargo e Justo (2013), com base na Teoria dos Grafos, a análise de similitude "possibilita identificar as coocorrências entre as palavras e seu resultado traz indicações da conexidade entre as palavras, auxiliando na identificação da estrutura da representação" (Camargo \& Justo, 2013, p. 6). Além disso, foram geradas nuvens de palavras para cada resumo $-n=27$ e $n=19$ - com a linguagem Python. Neste passo, os scripts para visualização de dados disponibilizados pelo LABCOM-UFMA foram adaptados para as necessidades desta pesquisa, de maneira a complementar as inferências junto à análise de similitude dos corpora.

\section{Inteligência artificial no contexto jornalístico}

É fato que, desde a década de 1970, a informática invadiu as redações estabelecendo um marco de revolução no que se refere à tecnologia e ao jornalismo (Marcondes Filho, 2009). Nas décadas de 2000 e 2010, as transformações pelas quais passa o jornalismo são discutidas sob uma perspectiva digital de possibilidade de trabalho com base de dados (Barbosa, 2007; Quadros, 2005; Salaverría, 2019; Träsel, 2014). $\mathrm{Na}$ contemporaneidade, o jornalismo é digital e o trabalho on-line requer novas habilidades por parte dos jornalistas, como o domínio de ferramentas tecnológicas para a busca de informações em base de dados e técnicas de visualização. Essa é uma perspectiva que vem sendo examinada como uma quinta geração no jornalismo (Barbosa, 2013). Todavia, tendo passado mais de 25 anos desde o surgimento do jornalismo on-line, em 1994, há inúmeras formas de denominação que tentam delimitar o fazer jornalístico no mundo digital. Web jornalismo, jornalismo digital, ciberjornalismo e jornalismo on-line são alguns exemplos da não existência de um nome comum (Salaverría, 2019).

Mais adiante, a discussão sobre a presença da IA se torna mais evidente no contexto jornalístico a partir do big data e de uma virada algorítmica na produção de notícias (Linden, 2018; Napoli, 2014). Aliado a isso, a apreensão em torno das fake news, da pós-verdade e da (des)credibilidade do jornalismo suscita discussões em torno das recentes práticas e premissas jornalísticas. A pesquisa Reuters Digital News Report, de 2017, realizada pelo Reuters Institute for the Study of Journalism em parceria com a Universidade de Oxford (Newman, Fletcher, Kalogeropoulos, Levy, \& Nielsen, 2017), contemplada em 36 países, revela que $54 \%$ dos entrevistados preferem algoritmos a editores e jornalistas para selecionar notícias. Os dados mostram que essa preferência é maior entre o público mais jovem que, consequentemente, está em maior contato com as mídias sociais. O relatório também revela o crescimento de

${ }^{1} \mathrm{O}$ relatório considera somente os Estados Unidos da América (EUA), a Inglaterra e a Alemanha, pois eram os países onde estes dispositivos estavam disponíveis à época da pesquisa. assistentes digitais controlados por voz, como a Alexa, desenvolvida pela Amazon, e da busca por notícias por meio destes dispositivos ${ }^{1}$.

Nesse contexto, o quakebot do Los Angeles Times é um exemplo de como os avanços tecnológicos estão presentes no jornalismo. Tal software, desenvolvido pelo jornalista e programador Ken Schwencke, em 2012, monitora alertas publicados pelo Serviço Geológico dos Estados Unidos (USGS). O bot foi treinado para acompanhar os dados e, mediante alertas de terremoto do USGS, escrever uma espécie de notícia. Esta é encaminhada para o editor, humano, que pode checar as informações e decidir pela publicação (What..., 2019). Se comparado ao que se espera de uma estrutura de notícia, apesar deste exemplo bastante rudimentar, é possível afirmar que os algoritmos estão avançando e são capazes de realizar as tarefas mais básicas em uma redação, como redigir um lead. "A automação e os algoritmos atingiram um ponto em sua maturidade em que podem realizar trabalhos reais de notícias - contribuindo para o empreendimento jornalístico de várias maneiras" (Diakopoulos, 2019, p. 62, tradução nossa). Mais recentemente surgiram outros exemplos de algoritmos, como a FactMachine, IA do site jornalístico Aos Fatos. Conhecida popularmente como Fátima, a robô auxilia o público na checagem de notícias que circulam no Twitter, no Messenger do 
${ }^{2} \mathrm{O}$ deep learning (aprendizado profundo) é um subcampo do machine learning (aprendizado de máquina) e consiste na execução de modelos matemáticos mais complexos que envolvem linguagem natural e processamento de imagens. Para o Jornalismo, um conjunto de algoritmos representa softwares capazes de atuar e interagir mais próximo do cognitivo humano utilizando algoritmos modernos de Processamento de Linguagem Natural (PLN), criando, por exemplo, os robôs apresentadores de telejornal que são discutidos no trabalho de Barcelos (2019). Já as técnicas de machine learning podem monitorar banco de dados estruturados e redigir textos simples, como é caso do quakebot do LA Times. Neste caso, a tecnologia empregada é a Natural Language Generation (NLG), ou Geração de Linguagem Natural. Os bancos de dados estruturados são aqueles organizados em uma estrutura planejada, como planilhas. Os bancos de dados não estruturados são os que não possuem qualquer estrutura, sendo dinâmicos, flexíveis, como as redes sociais digitais, em que textos, fotos, vídeos, áudios compõem este tipo de banco.
Facebook e no WhatsApp. Outros projetos que utilizam técnicas de deep learning ${ }^{2}$, como o Deepnews.ai, prometem identificar um jornalismo de qualidade, por meio de indicadores, no sentido de preservar e promover a democracia diante de um cenário de desinformação.

Durante o evento da Global Editors Network de 2019, o GEN Summit 2019, realizado em junho de 2020 em Atenas, na Grécia, o editor-chefe da Bloomberg News, John Micklethwait, revelou que ao menos um terço da produção diária de notícias já utiliza algum nível de automação na redação (Micklethwait, 2019). Alguns exemplos são a produção de notícias automatizadas, em que os algoritmos extraem dados e produzem a manchete e auxiliam na transcrição de gravações, na busca por pautas nas redes sociais digitais e na personalização do conteúdo que será entregue ao leitor, atuando como uma espécie de curadoria. A inovação está presente também na televisão, sobretudo nos países asiáticos que já possuem robôs apresentadores de telejornal (Barcelos, 2019).

A temática envolvendo o algoritmo e o futuro da produção de notícias, que trata a produção como automatizada, vem sendo pesquisada no âmbito acadêmico por diversos autores (Anderson, 2012; Diakopoulos, 2019; Latar, 2018; Lima Junior 2011; Linden, 2018; Marconi, 2020; Napoli, 2014; Santos, 2016). Ademais, diante dos avanços da IA nas redações, há algumas discussões acerca da garantia da democracia nos processos de investigação da notícia (Latar, 2018). Dentre os temas, ainda, encontra-se a preocupação sobre a extinção da profissão do jornalista: "Recentemente, as notícias geradas por softwares (chamadas equivocadamente de 'jornalismo robótico') passaram a ter destaque em razão de a automação das notícias poder tornar os jornalistas desnecessários" (Linden, 2018, p. 6). Outros pesquisadores destacam que, enquanto a tecnologia - algoritmos e o big data pode estar findando o jornalismo, ela também pode, no mesmo sentido, conter as sementes para o seu renascimento (Anderson, 2012). Essa argumentação ganha notoriedade a partir dos múltiplos olhares para a crise enfrentada pelo jornalismo nos últimos anos da década de 2010, um fenômeno complexo e dinâmico que abrange não apenas as questões financeiras (Christofoletti, 2019), mas que também inclui a descentralização da imprensa enquanto principal instituição mediadora da informação. Nesse sentido, um jornalismo com ênfase computacional vem sendo sugerido como uma possível solução para um cenário de crise, em especial nos aspectos econômicos e de sustentabilidade da produção de notícias (Diakopoulos, 2019) e da possibilidade de colaboração entre humanos e máquinas (Marconi, 2020). Contudo, tais perspectivas também são confrontadas face aos campos de força em que o jornalismo está situado: "Se as práticas computacionais são a salvação do jornalismo, esta salvação é certamente uma faca de dois gumes e depende de uma série de instituições sociais e artefatos tecnológicos que estão fora do próprio jornalismo" (Anderson, 2012, p. 6, tradução nossa).

Essa breve contextualização não dá conta, naturalmente, de todas as publicações na intersecção entre os temas IA e jornalismo, que, em sua amplitude, concebem inúmeros desdobramentos. Outros trabalhos investigam, por exemplo, como o uso da NLG pode ser empregado na rotina de produção jornalística, o que caracteriza as notícias como automatizadas (Carreira \& Squirra, 2017; Fiebig \& Quadros, 2020; Santos, 2016). Em termos práticos, há diferentes exemplos de como a IA vem sendo utilizada nas redações jornalísticas, seja por meio das técnicas de machine learning e deep learning ou de redes neurais artificiais no levantamento, checagem e redação das notícias (Dicas..., 2021).

A próxima seção apresenta os resultados que fazem vistas a como esse cenário vem sendo apreciado e discutido nos estudos acadêmicos realizados por pesquisadores brasileiros.

\section{Jornalismo e inteligência artificial: tendências nas pesquisas brasileiras}

Nesta seção, os resultados serão apresentados, primeiramente, de maneira quantitativa. Inicialmente, será abordado o levantamento geral dos artigos publicados em periódicos ( $n=262)$, base da qual foram escolhidos os três periódicos brasileiros com maior número de publicações que compõem o corpus $(n=19)$. Da base $n=262$, 
são apresentados os periódicos com maior quantitativo de publicação, os anos de publicação e os pesquisadores que mais publicaram entre 2010 e 2020. Depois, serão apresentados os resultados dos periódicos brasileiros $(n=19)$ e dos congressos nacionais ( $n=27)$. Na sequência, uma subseção traz os resultados da etapa qualitativa, organizados por $n=19$ e $n=27$.

\section{Breve panorama dos artigos publicados em periódicos}

No período investigado - 2010 a 2020-, os artigos (n=262) estão concentrados em três periódicos da Inglaterra (Gráfico 1): Digital Journalism (22\%), Journalism Pratice (5\%) e Journalism Studies (5\%). Estes achados são similares aos de Rubio e Ruiz (2021), que apontam a Digital Journalism como a que tem o maior volume de publicações entre 2008 e 2019. Já o periódico brasileiro melhor colocado neste quantitativo é o Brazilian Journalism Research, da SBPJor, com nove artigos publicados (3\%).
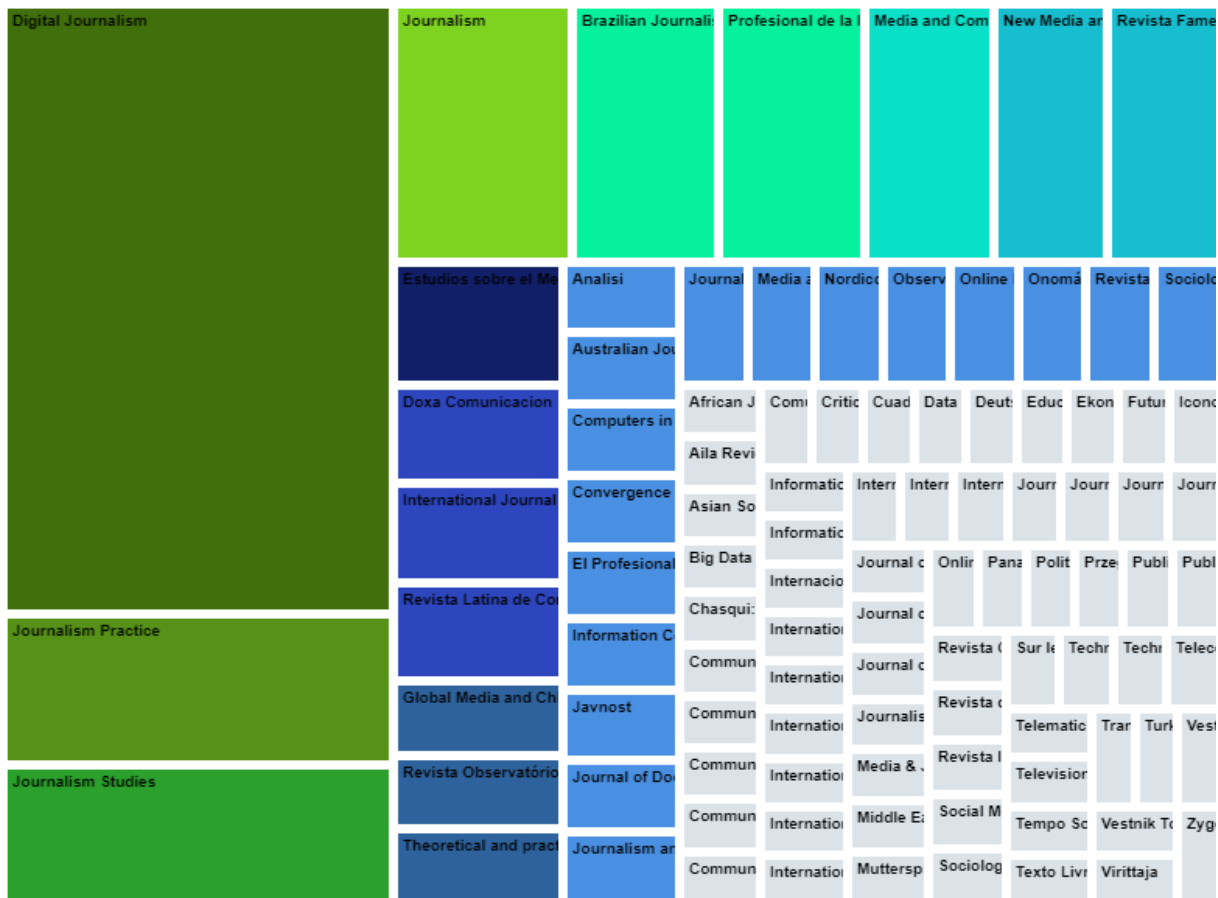

Gráfico 1: Periódicos que concentram maior número de artigos Nota: elaborado pela autora (2021) com base em 262 artigos.

Com relação ao ano de publicação, é notório um crescimento da temática a partir de 2015 (Gráfico 2). Com os métodos adotados, não foram encontrados artigos publicados em 2010. Entretanto, os resultados convergem com o levantamento realizado por Rubio e Ruiz (2021), que também aponta um crescimento do número de artigos publicados em periódicos a partir de 2015. Conforme já evidenciado em outras pesquisas, a percepção da importância e o interesse pelo tema é recente (Lima Junior, 2011).

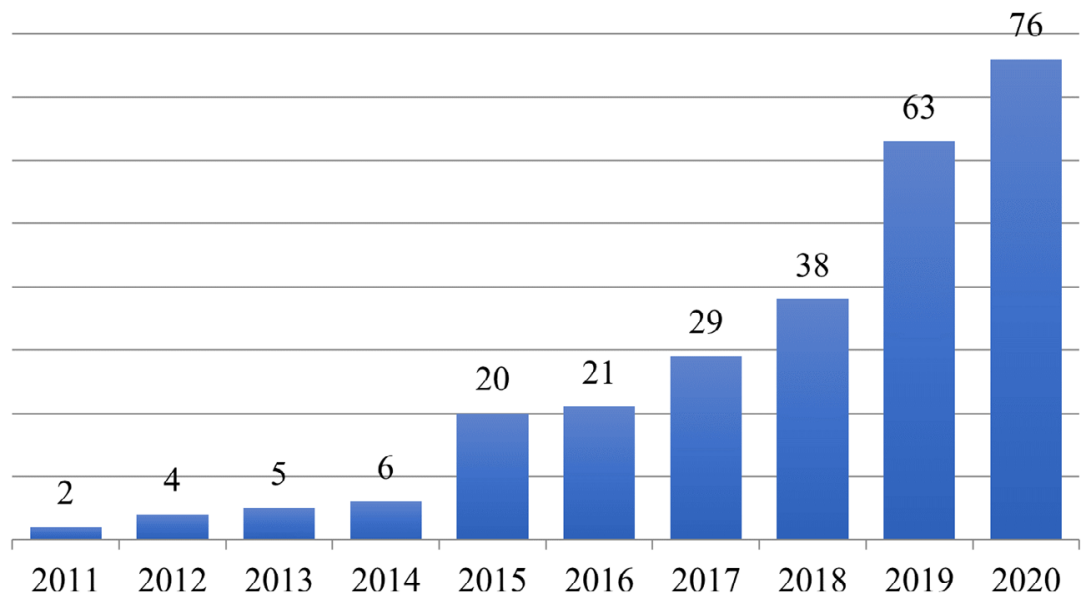

Gráfico 2: Quantidade de artigos publicados em periódicos entre 2011 e 2020 Nota: elaborado pela autora (2021) com base em 262 artigos. 
Foram identificados seis pesquisadores com maior quantitativo de publicação (Gráfico 3). O professor Neil Thurman, do Institute of Communication Studies and Media Research da Ludwig Maximilians University Munich (LMU) em Müchen, na Alemanha, tem o maior número de publicações, sendo, inclusive, um dos dois pesquisadores que aparecem em 2011. O seu artigo "Making 'the daily me': technology, economics and habit in the mainstream assimilation of personalized News" (2011), publicado na Journalism, trata das implicações dos algoritmos, a personalização do conteúdo e o contexto econômico jornalístico.

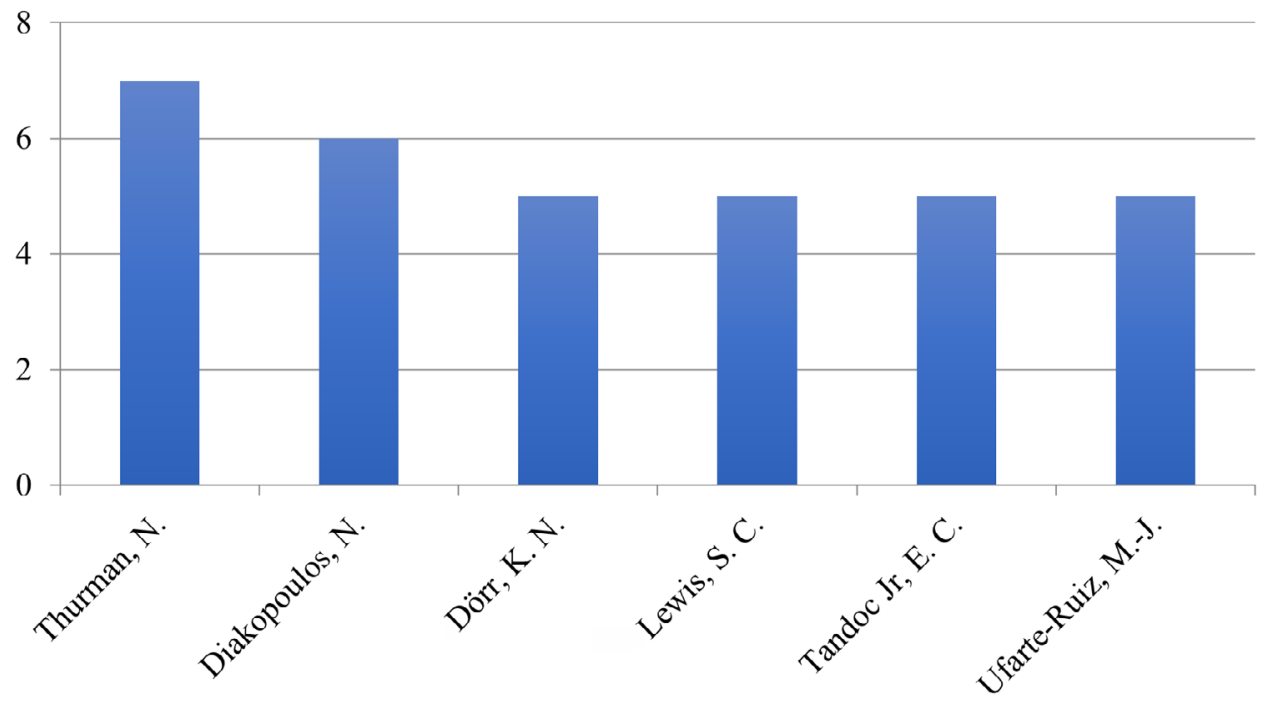

Gráfico 3: Pesquisadores que mais publicaram nos periódicos

Nota: elaborado pela autora (2021) com base em 262 artigos.

Entre os pesquisadores brasileiros na base estão Walter Teixeira Lima Junior, professor da Universidade Federal de São Paulo (Unifesp), com três artigos publicados - um deles em 2011 no International Journal of Interdisciplinary Social Sciences, intitulado "Recommendation systems that establish new forms of representational reality: eliminating the dividing line between information emitter and receptor of journalistic information", que analisa os sistemas de recomendação na web, as mudanças na experiência do usuário e as consequências naquilo que denomina como estrutura fundamental do jornalismo.

O outro pesquisador é Marcio Carneiro dos Santos, professor da Universidade Federal do Maranhão (UFMA), que tem três artigos publicados. O levantamento aponta que o primeiro artigo foi publicado em 2015 na Revista Observatório sob o título "Digital methods and the memory accessed by APIs: development tool for extracting data from journalistic portals with the wayback machine", que explora a possibilidade de automação da coleta de dados na web e o uso da linguagem de programação Python na construção de ferramentas úteis ao jornalismo.

\section{Quantitativo acerca dos periódicos brasileiros}

A partir da base $(n=262)$, foi estabelecido um recorte para os três periódicos brasileiros com maior quantitativo - Brazilian Journalism Research, Revista FAMECOS e Revista Observatório-, que, juntos, somam 19 artigos. Os resultados apresentados a partir desta seção se referem exclusivamente a este corpus $(n=19)$.

Em relação ao quantitativo anual por periódico (Gráfico 4), destaca-se o volume de publicações na Brazilian Journalism Research. Em 2020, o periódico publicou um dossiê, intitulado Journalism and algorithms, com nove artigos, dos quais seis foram encontrados a partir da combinação de palavras-chave da busca deste levantamento. 


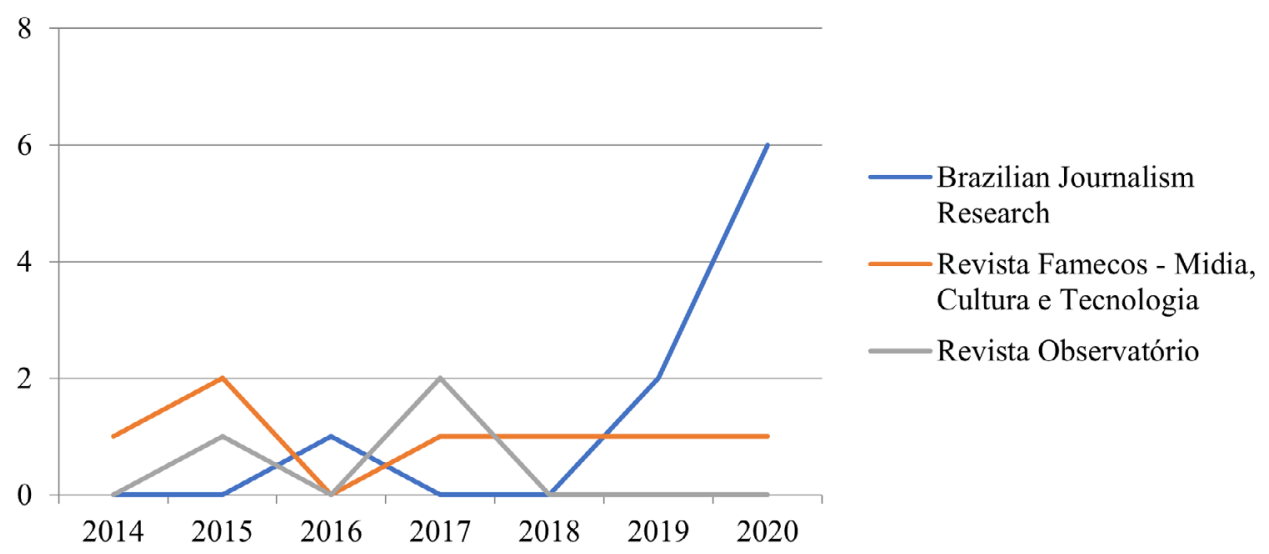

Gráfico 4: Quantitativo anual por periódico brasileiro Nota: elaborado pela autora (2021).

As 76 palavras-chave destes artigos foram organizadas em uma nuvem de palavras para a melhor visualização das mais frequentes (Figura 1). Dentre os principais termos observados, para além de jornalismo e IA, aparecem algoritmo (algorithm), automatizado (automated), dados (data) e notícias (news). No levantamento de Rubio e Ruiz (2021), as palavras-chave mais frequentes são Jornalismo Computacional (computational journalism, 33\%), jornalismo automatizado (automated journalism, $15,8 \%$ ) e jornalismo robô (robot journalism, 15,2\%). Embora sejam terminologias diferentes, estas expressões se encontram em convergência com a temática mais abrangente, a IA.
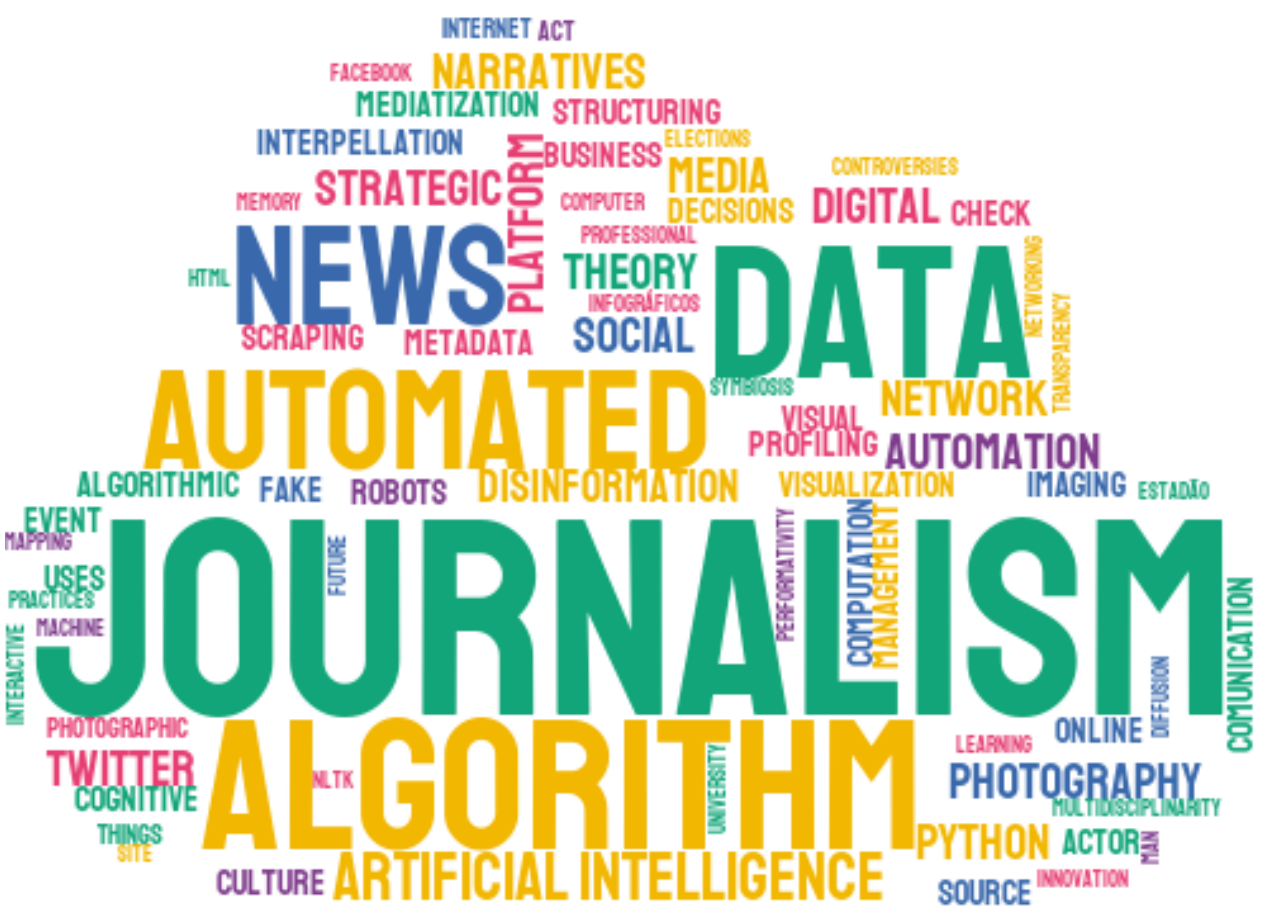

Figura1: Nuvem de palavras a partir das palavras-chave dos artigos Nota: elaborada pela autora (2021).

O termo algoritmo evidenciado nos artigos brasileiros trata da base dos processos de inovação ocasionados pela computação. Portanto, o algoritmo, uma sequência finita de regras, conforme a Matemática, ou, ainda, segundo a Informática, um conjunto de operações lógicas compreendidas por um computador, vem sendo relacionado à área de Comunicação num contexto de inovação tecnológica. Por outro lado, a possibilidade de um trabalho jornalístico a partir de um pensamento lógico e, até mesmo, baseado em uma racionalidade numérica - por meio de algoritmos -é criticada, tendo em vista as propriedades biológicas do cérebro humano. Autores como Latar (2018) defendem que as ferramentas de IA podem ser ótimas para propósitos científicos com a finalidade de testar hipóteses: "Elas são uma grande invenção para a expansão do conhecimento, mas estas conexões devem ser 
devidamente validadas se realmente querem agregar um valor real ao conhecimento humano" (Latar, 2018, p. 335). Outros olhares apontam para o futuro presente das redações num cenário de colaboração entre máquinas e humanos (Marconi, 2020).

Outros indicativos acerca das palavras-chave mostram termos como redes sociais digitais (network), mídia (media), Twitter, Python, narrativas (narratives), plataforma (plataform), estratégico (strategic), digital (digital), desinformação (disinformation) e automação (automation). A linguagem de programação Python vem aparecendo nos estudos da área de Comunicação como uma ferramenta, uma vez que o Jornalismo, desde os seus primórdios, sempre esteve ligado a algum tipo de tecnologia, a exemplo da prensa de Gutenberg (Santos, 2016). De acordo com Santos (2016), a Python é uma linguagem de fácil compreensão para jornalistas. É, portanto, considerada uma ferramenta de destaque para a construção de narrativas automatizadas. Nessa mesma linha, DalBen e D’Andréa (2017) argumentam sobre a necessidade do jornalista se familiarizar com linguagens de programação como a Python diante do contexto crescente do big data e da adoção de softwares de NLG para produzir conteúdo automatizado nas redações.

O levantamento quantitativo mostra os autores e coautores conforme o ano de publicação e o periódico (Quadro 2). Novamente, os autores Marcio Carneiro dos Santos e Walter Teixeira Lima Junior despontam com maior quantidade, com três e dois artigos, respectivamente. O corpus $(n=19)$ é contabilizado por nove artigos publicados na Brazilian Journalism Research, sete artigos na Revista FAMECOS e três artigos na Revista Observatório.

\begin{tabular}{|c|c|c|c|}
\hline Autor & Coautores & Ano & Periódico \\
\hline Santos, M. C. & - & 2020 & Brazilian Journalism Research \\
\hline Santos, M. C. & - & 2016 & Brazilian Journalism Research \\
\hline Santos, M. C. & - & 2015 & Revista Observatório \\
\hline Lima Jr., W. T. & Oliveira, A. R. & 2017 & $\begin{array}{l}\text { Revista FAMECOS - Mídia, } \\
\text { Cultura e Tecnologia }\end{array}$ \\
\hline Lima Jr., W. T. & - & 2017 & Revista Observatório \\
\hline Dalben, $\mathrm{S}$. & - & 2020 & Brazilian Journalism Research \\
\hline Kaufman, D. & Santaella, L. & 2020 & $\begin{array}{l}\text { Revista FAMECOS - Mídia, } \\
\text { Cultura e Tecnologia }\end{array}$ \\
\hline Dierickx, L. & - & 2020 & Brazilian Journalism Research \\
\hline Jurno, A. C. & D’Andréa, C. & 2020 & Brazilian Journalism Research \\
\hline Gehrke, M. & Benetti, M. & 2020 & Brazilian Journalism Research \\
\hline Oliveira, D. B. & $\begin{array}{l}\text { Guimarães Da } \\
\text { Costa, B. C. }\end{array}$ & 2020 & Brazilian Journalism Research \\
\hline Castro, J. C. L. & - & 2019 & $\begin{array}{l}\text { Revista FAMECOS - Mídia, } \\
\text { Cultura e Tecnologia }\end{array}$ \\
\hline Oliveira, A. P. & Angeluci, A. C. B. & 2019 & Brazilian Journalism Research \\
\hline Júnior, D. B. R. & $\begin{array}{l}\text { Lins, A. J. C.; Souza, } \\
\text { A. C. F.; Libório, L. F. } \\
\text { O.; Leitão, A. H. B.; } \\
\text { Santos, F. H. S. }\end{array}$ & 2019 & Brazilian Journalism Research \\
\hline Rodrigues, F. & Capoano, E. & 2018 & $\begin{array}{l}\text { Revista FAMECOS - Mídia, } \\
\text { Cultura e Tecnologia }\end{array}$ \\
\hline Carreira, K. & Squirra, S. & 2017 & Revista Observatório \\
\hline Marcondes Filho, C. & - & 2015 & $\begin{array}{l}\text { Revista FAMECOS - Mídia, } \\
\text { Cultura e Tecnologia }\end{array}$ \\
\hline Hoffmann, M. L. & Oliveira, M. & 2015 & $\begin{array}{l}\text { Revista FAMECOS - Mídia, } \\
\text { Cultura e Tecnologia }\end{array}$ \\
\hline Lemos, A. L. M. & Rodrigues, L. P. B. & 2014 & $\begin{array}{l}\text { Revista FAMECOS - Mídia, } \\
\text { Cultura e Tecnologia }\end{array}$ \\
\hline
\end{tabular}

Quadro 2: Autores e coautores nos periódicos brasileiros

Nota: elaborado pela autora (2021). 
No total, são 31 autores e coautores que publicaram nos periódicos no período investigado. Em comparação com o estudo realizado por Quadros, Mielkniczuk e Barbosa (2006), Sebastião Squirra, professor da Universidade Metodista de São Paulo (UMESP), tem destaque. O pesquisador marca presença em uma linha do tempo de estudos, sendo o primeiro autor a publicar um livro no Brasil sobre jornalismo digital, em 1998. Também foi orientador da tese de Walter Teixeira Lima Junior, defendida em 2003 na Universidade de São Paulo (USP).

\section{Quantitativo acerca dos congressos brasileiros}

Nos anais publicados nos sites dos congressos brasileiros, foram encontrados 27 artigos. Destes, 14 foram publicados no Intercom, 12 no SBPJor e 1 na Compós. Os trabalhos são, na maioria, provenientes de IES situadas na região Sudeste (48\%). Já a região Sul aparece com $41 \%$ dos artigos e a região Norte com $11 \%$. Entre os destaques das produções das IES está a Universidade Federal de Santa Catarina (UFSC), que possui o maior quantitativo de trabalhos - sete dos 27 artigos no total (Tabela 3).

\begin{tabular}{l|l|c|c}
\hline IES & Região & UF & Quantidade \\
\hline Universidade Federal de Santa Catarina (UFSC) & Sul & SC & 7 \\
\hline Universidade Metodista de São Paulo (UMESP) & Sudeste & SP & 4 \\
\hline Universidade de São Paulo (USP) & Sudeste & SP & 3 \\
\hline $\begin{array}{l}\text { Pontifícia Universidade Católica do Rio de Janeiro } \\
\text { (PUC-Rio) }\end{array}$ & Sudeste & RJ & 2 \\
\hline Universidade Federal do Paraná (UFPR) & Sul & PR & 2 \\
\hline $\begin{array}{l}\text { Escola Superior de Propaganda e Marketing } \\
\text { (ESPM-Rio) }\end{array}$ & Sudeste & RJ & 1 \\
\hline Pontifícia Universidade Católica do Paraná (PUC-PR) & Sul & PR & 1 \\
\hline Universidade Estadual Paulista (UNESP) & Sudeste & SP & 1 \\
\hline Universidade Federal da Paraíba (UFPB) & Nordeste & PB & 1 \\
\hline Universidade Federal de Minas Gerais (UFMG) & Sudeste & MG & 1 \\
\hline Universidade Federal do Maranhão (UFMA) & Nordeste & MA & 1 \\
\hline Universidade Federal do Piauí (UFPI) & Nordeste & PI & 1 \\
\hline $\begin{array}{l}\text { Universidade Federal do Rio Grande do Sul } \\
\text { (UFRGS) }\end{array}$ & Sul & RS & 1 \\
\hline Universidade Federal Fluminense (UFF) & Sudeste & RJ & 1 \\
\hline Total & & & $\mathbf{2 7}$ \\
\hline
\end{tabular}

Tabela 3: Produção por IES

Nota: elaborada pela autora (2021).

Não foram identificados, por meio dos métodos e das técnicas adotados neste levantamento, artigos oriundos de IES das regiões Norte e Centro-Oeste. Além disso, o corpus ( $n=27$ ) é representado em $70 \%$ por universidades públicas e em $30 \%$ por universidades privadas.

Embora contemple um recorte temporal de uma década (2010-2020), este estudo não encontrou artigos anteriores a 2014 (Gráfico 5). Ademais, nos anais dos congressos brasileiros, 2020 e a SBPJor têm maior destaque. Numa breve comparação com o quantitativo anual dos periódicos (Gráfico 2), nota-se que é a partir de 2015 que os trabalhos passam a ter um maior volume, indo de encontro ao que já foi referenciado na literatura por Lima Junior (2011). 


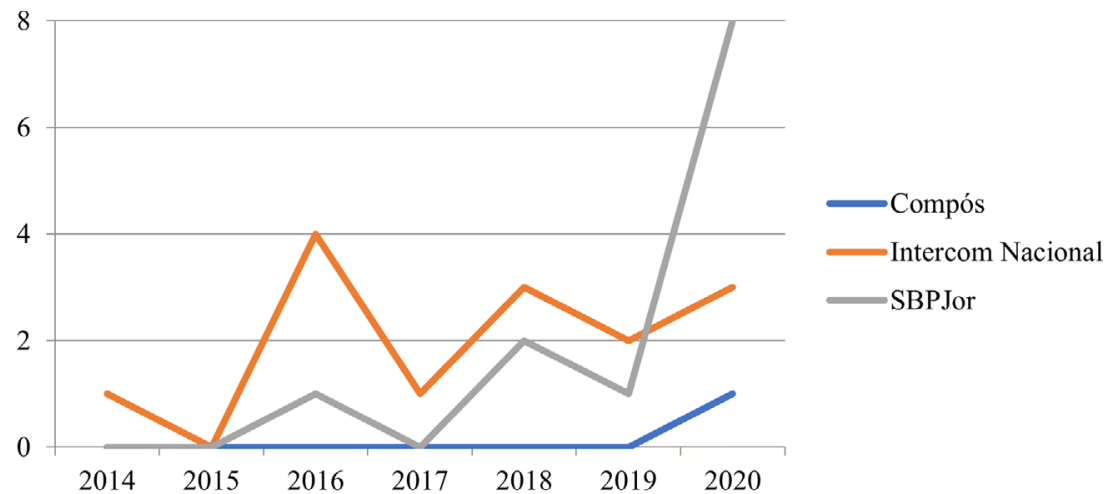

Gráfico 5: Quantitativo anual nos anais dos congressos Nota: elaborado pela autora (2021).

Dos seis pesquisadores que mais publicaram nos congressos brasileiros (Gráfico 6), Kérley Winques, pesquisadora do Núcleo de Estudos e Produção Hipermídia Aplicados ao Jornalismo (NEPHI-Jor) da UFSC e professora no Instituto Superior e Centro Educacional Luterano Bom Jesus (IELUSC) merece destaque. De maneira geral, os artigos publicados pela autora evidenciam etapas de pesquisa e os resultados da sua tese, defendida no Programa de Pós-Graduação em Jornalismo (PPGJOR) da UFSC acerca das mediações algorítmicas.

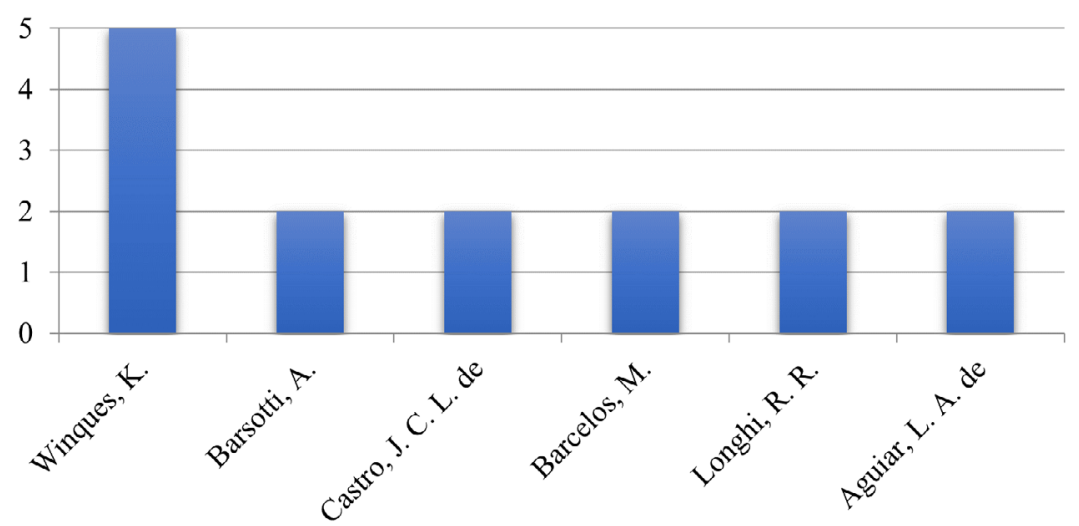

Gráfico 6: Pesquisadores que mais publicaram nos congressos brasileiros Nota: elaborado pela autora (2021).

De um total de 122 palavras-chave presentes nos artigos, as palavras algoritmo, robô, dados, redes sociais e notícia têm destaque. Desse modo, a nuvem de palavras da Figura 2 tem similaridades com a nuvem palavras dos periódicos (Figura 1) para os termos notícia, dado, redes sociais e desinformação.

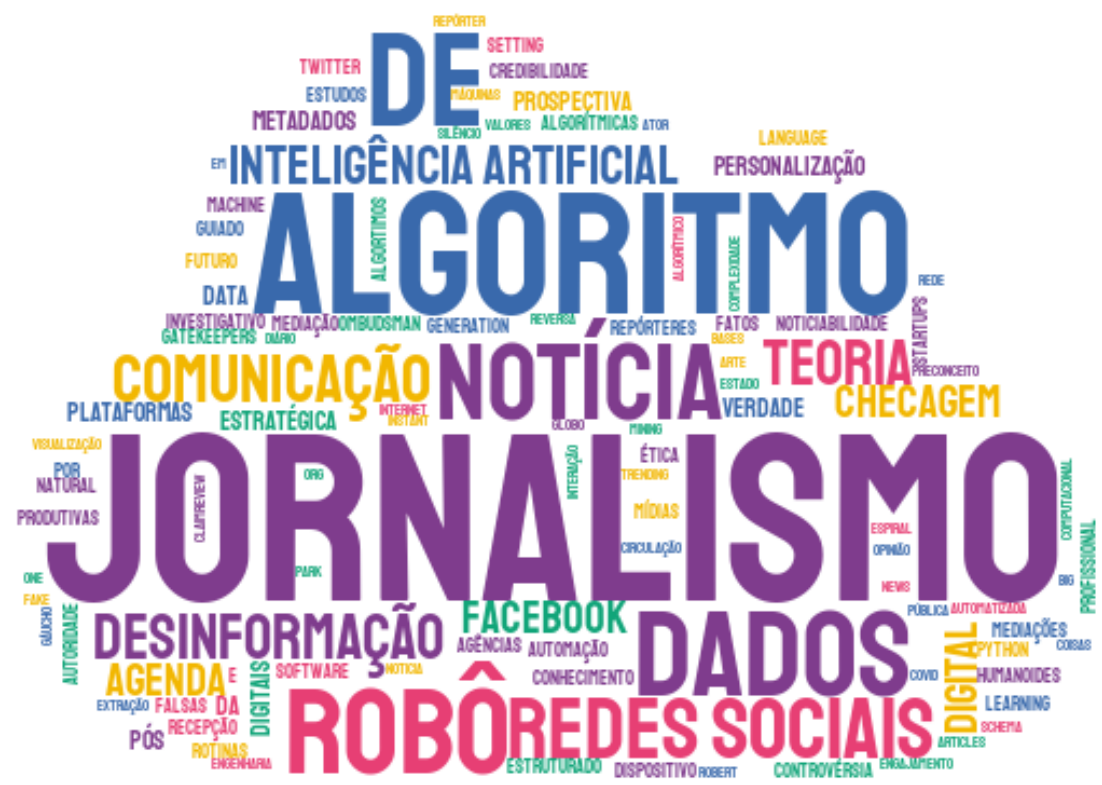

Figura 2: Nuvem de palavras a partir das palavras-chave dos artigos Nota: elaborada pela autora (2021). 
Vale ressaltar a palavra-chave robô, que aparece em destaque na Figura 2, mas que não aparece com tanto destaque na nuvem de palavras referentes aos artigos publicados em periódicos. Além disso, termos que foram identificados nas palavraschave dos periódicos (Figura 1), como linguagens de programação, narrativas e automação, não estão evidentes nas palavras-chave dos artigos publicados em congressos brasileiros. Todavia, isso não significa que esses trabalhos não discutem tais perspectivas; a percepção do que está presente nos trabalhos é analisada com abordagem qualitativa, a partir de inferências das coocorrências e conexões entre as palavras, cujos resultados são apresentados na próxima seção.

\section{Principais inferências a partir da abordagem qualitativa}

Na segunda etapa, utilizando a análise de similitude do software Iramuteq (Marchand \& Ratinaud, 2012), que tem por base a Teoria dos Grafos, foi possível identificar as ocorrências entre as palavras que compõem os resumos publicados nos periódicos $(n=19)$ e nos congressos $(n=27)$ e suas respectivas conexões.

\section{Periódicos e a centralidade nas tecnologias e na produção de notícias}

A partir da leitura dos títulos dos artigos e considerando a nuvem de palavras da Figura 1, foi possível fazer inferências acerca da estrutura do conteúdo por meio das coocorrências e das conexões entre as palavras dos resumos de periódicos (Figura 3). Desse modo, três palavras têm maior destaque nos resumos: news (notícia), datum (dados) e journalism (jornalismo).

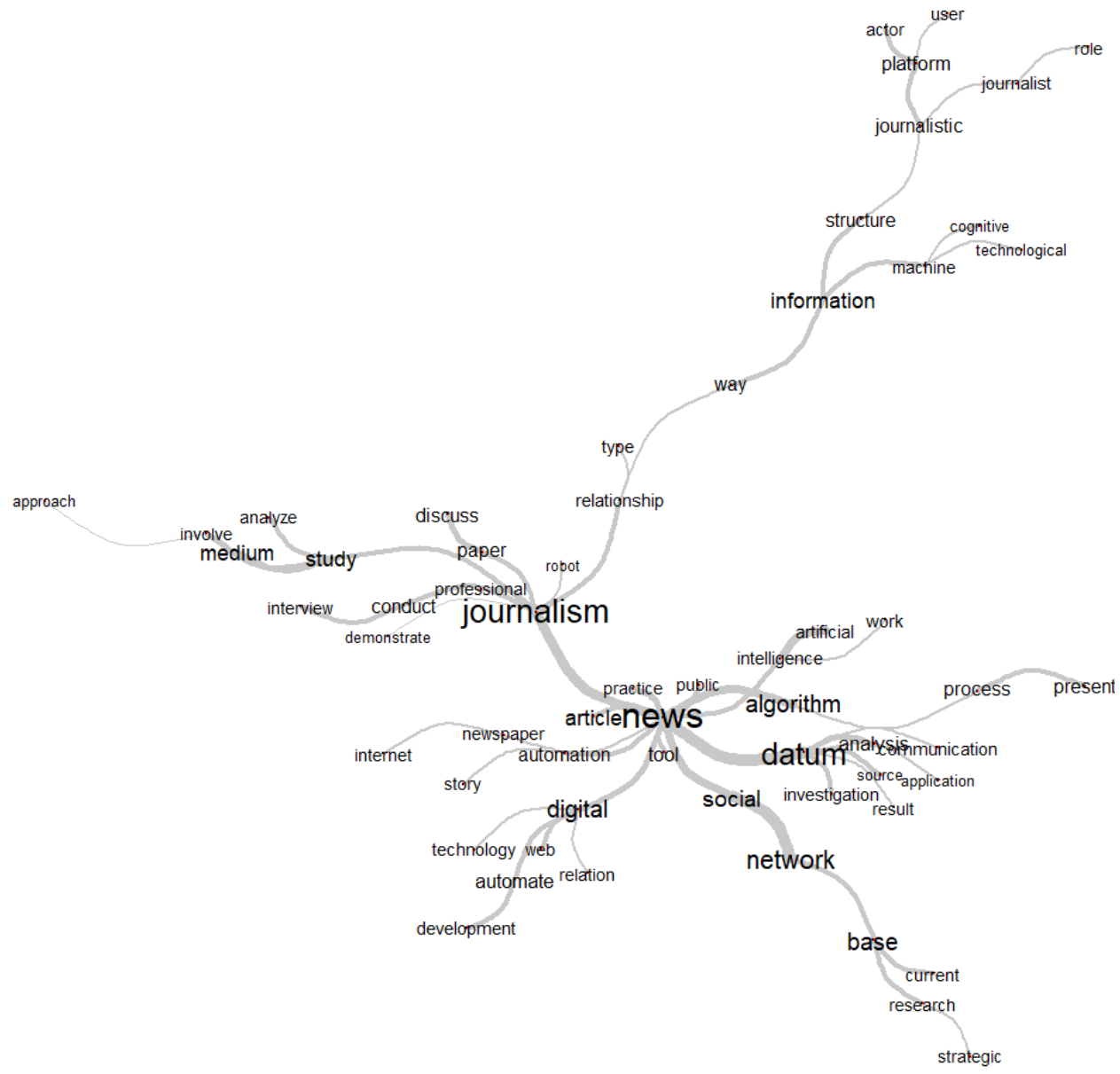

Figura 3: Análise de similitude dos resumos em periódicos Nota: elaborada pela autora (2021).

A palavra news se conecta com termos como practice (prática), tool (ferramenta), public (público), automation (automação) e, mais adiante, com Artificial Intelligence (Inteligência Artificial) e work (trabalho), além da própria questão do algoritmo. É possível inferir que esses trabalhos possuem uma inclinação às implicações da automação nas notícias, embora a questão da plataformização (Poell, Nieborg, \& van Dijck, 2020) não esteja situada diretamente nessas conexões. 
A palavra platform (plataforma) está ligada ao papel do jornalista (journalist role), do usuário (user) e ator (actor) e do jornalístico (journalistic) e aparece ao extremo das conexões do jornalismo que, por este ramo da árvore, trata da relação (relationship), da informação (information), da estrutura (structure), da máquina (machine), do tecnológico (technological) e do cognitivo (cognitive). Nota-se que a discussão a partir dos resumos dos periódicos fica centrada nas redes sociais digitais numa extensão do nó news. Em geral, esses trabalhos não articulam questões mais complexas relacionadas a um ecossistema midiático em torno da plataformização (van Dijck, 2014), numa abordagem mais abrangente, como a confiança nas instituições e as implicações das plataformas de redes sociais para o fazer jornalístico. Já, o termo datum (dados) faz conexões com result (resultado), source (fonte), analysis (análise), investigation (investigação), communication (comunicação) e application (aplicação) e traz inferências sobre os artigos que estão discutindo a natureza da pesquisa aplicada e da própria automação. Tais conexões permitem inferir que há uma preocupação com a tecnologia e a produção de notícias. Contudo, "...as mudanças tecnológicas e seus impactos, entretanto, não podem ser avaliados de forma isolada já que fatores sociais e econômicos parecem constituir também vetores imbricados no complexo cenário da mídia contemporânea" (Santos, 2016, p. 165). Além disso, esses resultados também vão de encontro com o levantamento de Rubio e Ruiz (2021), que destaca que os artigos publicados em periódicos, em sua maioria, estão centrados na descrição de ferramentas de IA e métodos para o desenvolvimento de atividades jornalísticas nas redações.

Ao organizar os resumos dos periódicos em uma nuvem de palavras com a linguagem Python (Figura 4), é possível visualizar que algoritmo (algorithm) tem destaque junto a termos como notícias (news), uso (use), dados (datum) e base (base). Essa visualização permite uma inferência acerca da possibilidade de veicular notícias a partir do uso de base de dados, tendo em vista os algoritmos.

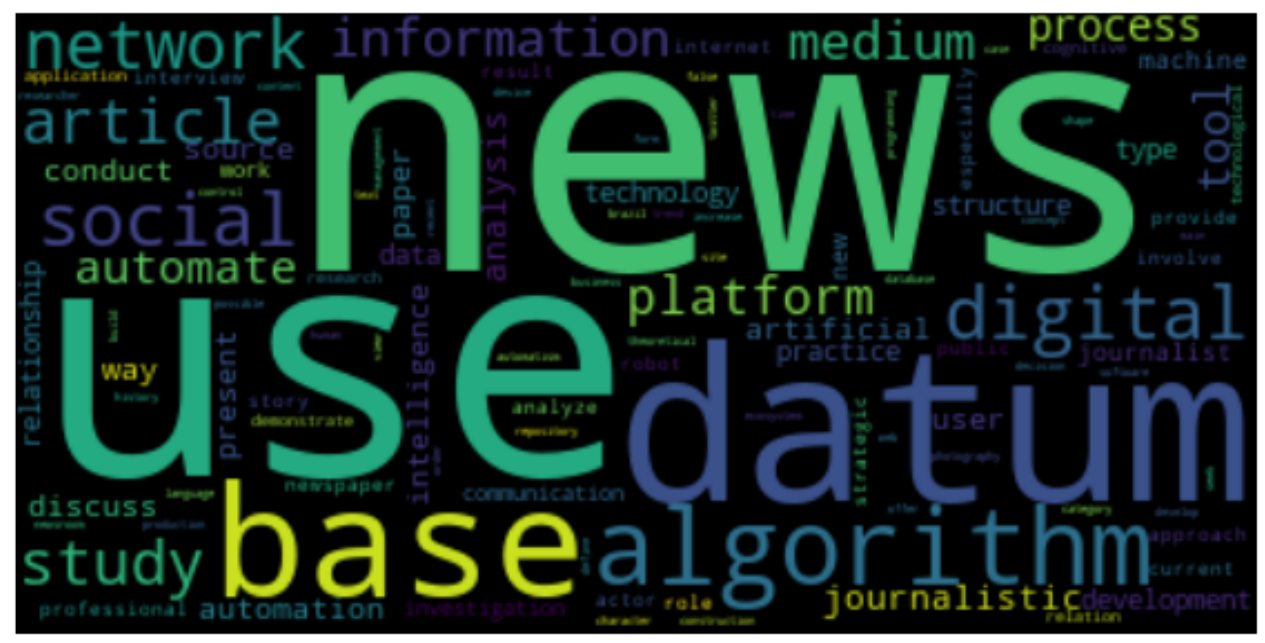

Figura 4: Nuvem de palavras dos resumos de periódicos Nota: elaborada pela autora (2021).

Em síntese, os resumos publicados nos periódicos $(n=19)$ inclinam suas inferências para uma perspectiva mais prática daquilo que ocorre nas redações jornalísticas, seja por meio da observação, enquanto um procedimento metodológico, ou pela maior propriedade dos conhecimentos técnicos necessários para lidar com os dados.

\section{$O$ algoritmo como destaque nos congressos}

Os resumos publicados nos congressos $(n=27)$ têm ao menos três termos com maior destaque: como, jornalismo e jornalístico (Figura 5). O nó da palavra como traz inferências sobre a particularidade dos trabalhos que buscam contribuir com algum tipo de resposta ou reflexão para as implicações dos algoritmos no jornalismo. 0 caminho entre as conexões mostra que a palavra como está relacionada à pesquisa bibliográfica, sugerindo que esses trabalhos, em sua maioria, trabalham com tal procedimento metodológico. Por outro lado, quando o termo está em conexão com jornalismo é possível observar outras palavras - debate, compreender, teoria, apresentar, estudo e análise - em uma ramificação em que a palavra dado também 
está presente. Ainda, a partir de um olhar para o nó é possível verificar a palavra notícia com termos como mediação, novo, tecnológico, impacto, conceito, produção e ferramenta, que trazem inferências sobre como as tecnologias, ora denominadas pelo dado e ora pelo algoritmo, ocupam as discussões.

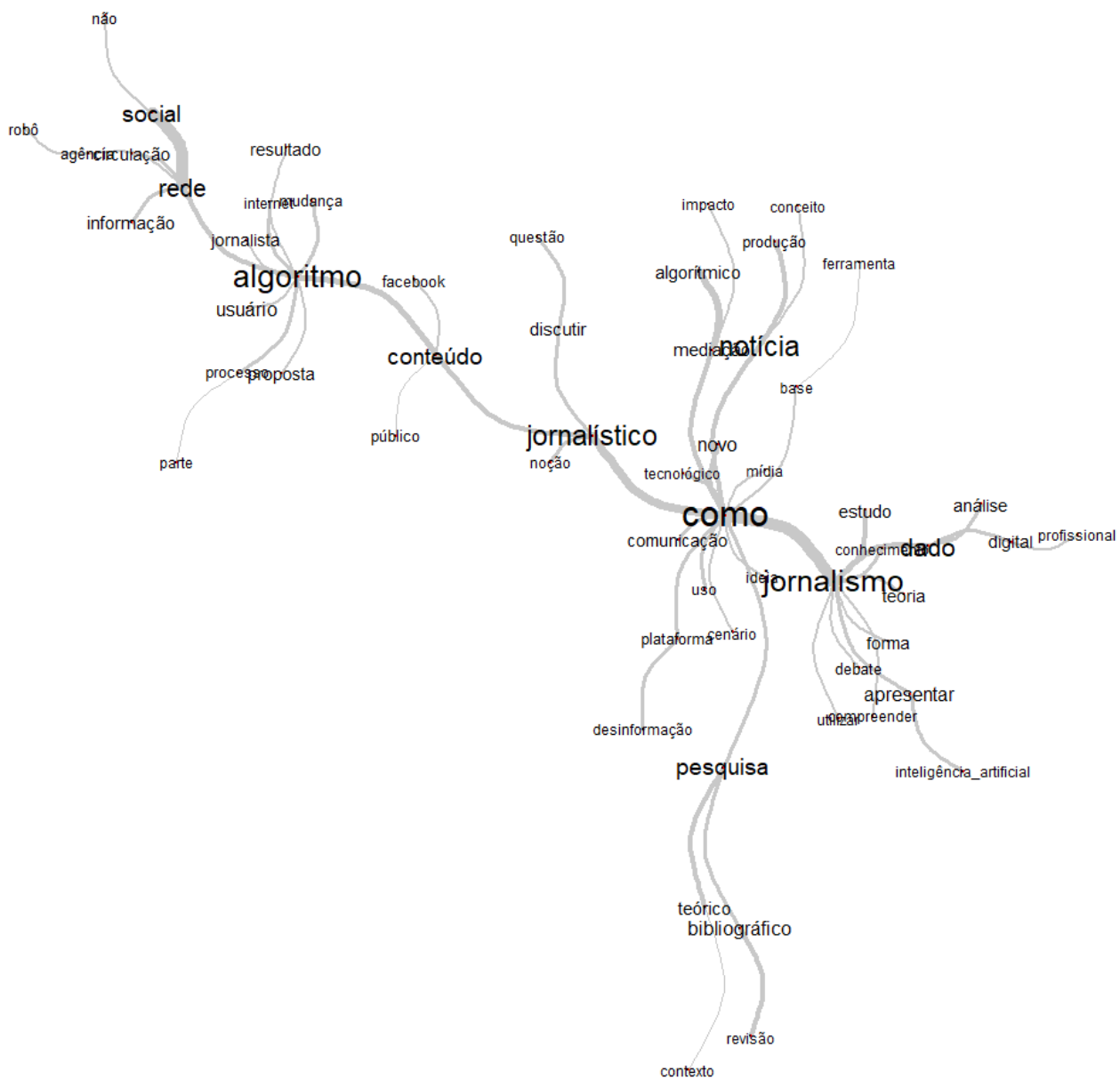

Figura 5: Análise de similitude dos resumos em congressos

Nota: elaborada pela autora (2021).

Ainda, o nó jornalístico faz conexões com conteúdo, algoritmo, Facebook, usuário, rede social, agência, circulação, internet e mudança, caracterizando as mudanças em relação às práticas jornalísticas. No levantamento realizado por loscote (2020) acerca dos trabalhos publicados nos congressos nacionais de Comunicação sob a temática da IA entre 2010 e $2019,53 \%$ dos artigos discutem o trabalho do jornalista - novas práticas, riscos e o futuro da profissão -, enquanto $33 \%$ articulam a questão do conteúdo automatizado e as suas implicações éticas, seus filtros e a necessidade de conhecer as operações algorítmicas. Tais inferências vão de encontro com as conexões que podem ser visualizadas a partir dos termos jornalístico, notícia e algoritmo. Nota-se também que o futuro do jornalismo, a circulação das notícias e as práticas no ambiente digital estavam entre os temas encontrados por Quadros, Mielkniczuk e Barbosa (2006). Nesse sentido, a notícia como um objeto inerente ao jornalismo (Franciscato, 2003) estará em permanente discussão, visto as mudanças e os avanços tecnológicos da sociedade.

A nuvem de palavras dos resumos em congressos, gerada a partir da linguagem Python (Figura 6), destaca, mais uma vez, os termos jornalismo, algoritmo e notícia. A preocupação em discutir essa tríade evidencia o que autores como Lima Junior (2011) vêm apontando sobre uma necessidade de entendimento, por parte dos jornalistas, sobre o funcionamento dos sistemas tecnológicos que suportam a mídia. De acordo com o autor, durante anos, tanto o ensino quanto a prática do Jornalismo estiveram longe dessa perspectiva. $O$ resultado é que a maior parte dos jornalistas crê que utilizar um computador, lidar com e-mails e redes sociais digitais seria o suficiente para entender o jornalismo contemporâneo (Lima Junior, 2011). 


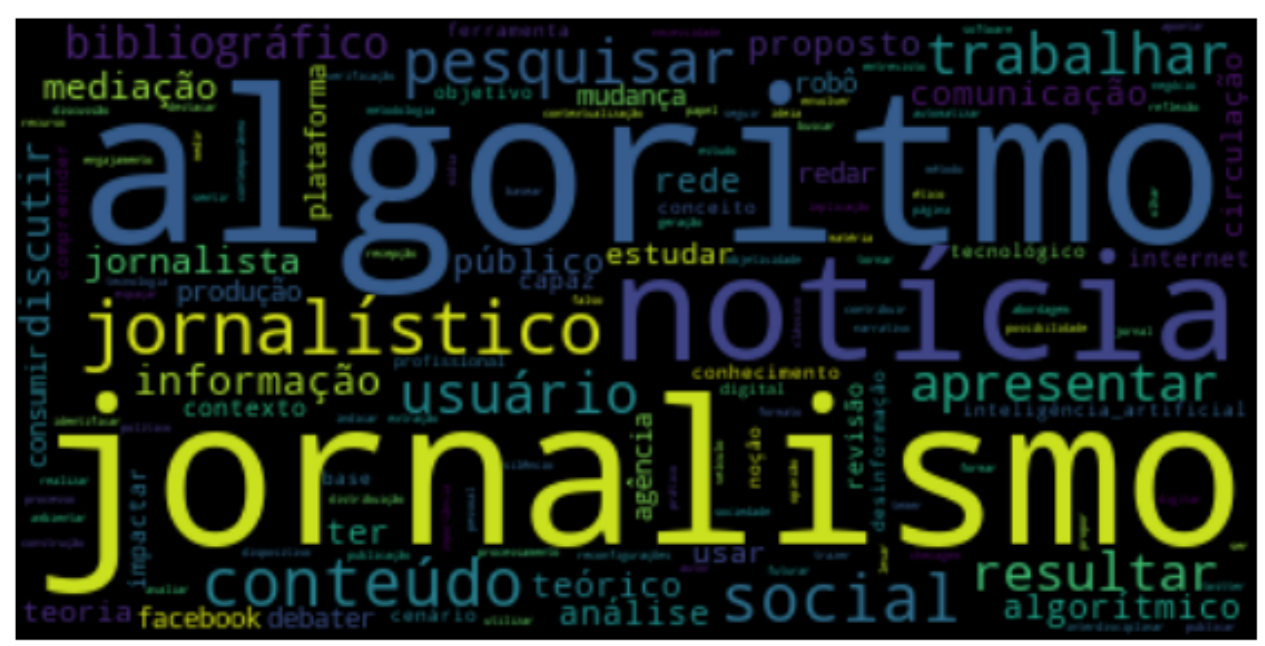

Figura 6: Nuvem de palavras dos resumos em congressos Nota: elaborada pela autora (2021).

Em linhas gerais, os resultados acerca das publicações em congressos $(n=27)$ permitem fazer inferências em relação a uma preocupação sobre como o algoritmo está articulado ao trabalho do jornalista, bem como sobre as suas implicações para a profissão. Reunindo os gráficos apresentados nesta subseção, com a leitura de títulos, resumos e palavras-chave, é possível afirmar que o algoritmo entra no debate acerca dos riscos para o ofício do jornalista ou, até mesmo, do próprio fim da profissão diante de softwares que são capazes de redigir notícias. Além disso, há uma preocupação em relação a como o algoritmo atua na mediação, circulação e distribuição das notícias, bem como no consumo, nas implicações com os filtros-bolha e na opacidade dos sistemas. Os trabalhos também se atentam às discussões mais específicas do campo jornalístico, como a agenda setting, o algoritmo como novo gatekeeper, valores-notícias e critérios normativos diante desse cenário. Ademais, discutem problemas relacionados à desinformação e à ética, além de também haver uma inclinação para a discussão das redes sociais digitais, em especial o Facebook.

\section{Considerações finais}

Este trabalho teve por objetivo, por meio de um estado da arte, verificar como o Jornalismo vem sendo estudado por pesquisadores brasileiros a partir de artigos apresentados em congressos e publicações em periódicos nacionais da área de Comunicação, sob a perspectiva do cenário da Inteligência Artificial. Por meio dos procedimentos metodológicos adotados, o recorte analisado apresenta dois caminhos trilhados nas discussões: 1 . nos periódicos, os artigos se concentram nas ferramentas e nas próprias questões relacionadas aos dados e daí surgem as possibilidades em pesquisas aplicadas; 2 . nos congressos, há a presença do termo algoritmo tensionado com as implicações junto ao trabalho do jornalista. Em relação aos estudos similares citados, no que se refere ao jornalismo digital, esses achados evidenciam possíveis mudanças ou rupturas em que o termo digital dá lugar aos algoritmos, à automação e à IA. Contudo, ruptura não seria o termo mais adequado, uma vez que as transformações percorrem o ambiente digital. Sendo assim, a mudança, a transformação ou a inovação no jornalismo diante de um contexto computacional poderiam oferecer reflexões mais oportunas sobre a IA, com o cuidado de não reduzir todas as possibilidades aos processos.

A partir dos resultados, é possível afirmar que, nos artigos publicados nos periódicos, há um pouco mais de conhecimento acerca das ferramentas, das bases de dados, do desenvolvimento de softwares e do uso de terminologias específicas - calibragem e iteração - que pertencem, em geral, à área da Ciência da Computação. Portanto, o termo algoritmo não está tão presente, porque dá lugar à automação ou aquilo que é - ou pode ser-automatizado no jornalismo, no caso, a notícia. Essa ênfase em uma possibilidade de trabalho jornalístico com dados surge por meio da proposta de ferramentas ou da observação sobre como a IA está sendo utilizada dentro das redações. Em aspectos metodológicos, essa abordagem é apresentada tanto por observação quanto por entrevistas com 
profissionais, caracterizando a descrição do uso da tecnologia nos processos de produção jornalística em redações automatizadas.

Em relação aos artigos publicados em congressos, o termo algoritmo aparece com maior destaque, sendo o centro da discussão em torno do jornalismo. Grosso modo, a partir de todo o material analisado referente a esses trabalhos, é possível afirmar que há uma preocupação excessiva com relação ao papel do algoritmo na atividade jornalística. Contudo, poucos trabalhos apresentam o domínio de um vocabulário mais especializado, como Natural Language Processing (NLP) - em português, Processamento de Linguagem Natural -, NLG, pipeline, metadata, cálculos, calibragem, iteração etc.

Destaca-se ainda que, apesar de os artigos se concentrarem na busca por ferramentas ou na discussão do trabalho do jornalista, não há estudos que tensionem a questão do ensino nos cursos de graduação. A partir do cenário digital e diante de tantas transformações, é preciso levar em consideração o que se ensina e quais competências profissionais o mercado absorve. O jornalista do futuro presente é o que escreve a linha de código? Em que sentido a computação ocupa lugar nas redações? Assim, olhar para a literatura é perceber um breve indicativo acerca das práticas do jornalismo na contemporaneidade, em que há, ao menos, três conjunturas: aquela assistida por computador - jornalismo digital -, a baseada em dados que são consultados, recuperados e extraídos - jornalismo de dados e de automação - e a mais atual, observada a partir da década de 2010, aquela com ênfase no uso da linguagem de programação e na necessidade do jornalista programador - jornalismo computacional.

Embora alguns pesquisadores defendam que não haja a necessidade de compreender o que é e como funciona um algoritmo, ou seja, apenas o reconhecimento da sua importância já é o suficiente para adentrar a discussão, é fundamental destacar que a compreensão do que é e do que se constitui um algoritmo computacional pode auxiliar uma visão mais crítica acerca do fenômeno da dataficação. Nesse sentido, um conhecimento mais refinado sobre o que é a IA, o big data, os algoritmos e as suas operações pode contribuir para a busca de soluções - como visto nos artigos publicados em periódicos, que tratam da possibilidade de desenvolvimento de ferramentas -e com as discussões relacionadas ao quanto há de inovação nestas ferramentas. Apesar de tratarem de inovações tecnológicas, ambos os corpora analisados não apresentaram termos como inovação ou apropriações, o que nos leva a outros questionamentos importantes para a área, como: será que há de fato inovação no jornalismo, ou apenas apropriações das ferramentas da Ciência da Computação? Sugere-se que este possa ser um caminho a ser pesquisado em investigações futuras, especialmente a partir das pesquisas aplicadas que descrevem ferramentas.

\section{Referências}

Anderson, C. W. (2012). Notes towards an analysis of computational journalism. SSRN Electronic Journal, 1, 1-22. https://doi.org/10.2139/ssrn.2009292

Barbosa, S. (2007). Jornalismo digital em base de dados (JDBD): Um paradigma para produtos jornalísticos digitais dinâmicos. [Tese de doutorado, Universidade Federal da Bahia]. Repositório Institucional UFBA. http://repositorio.ufba.br/ri/ handle/ri/11299

Barbosa, S. (2013). Jornalismo convergente e continuum multimídia na quinta geração do jornalismo nas redes digitais. Notícias e mobilidade: $O$ jornalismo na era dos dispositivos móveis, 102(6), 33-54.

Barcelos, M. (2019, novembro). Humanoides-repórteres, os robôs com inteligência artificial: Desafio real ou fetiche tecnológico? [Apresentação de trabalho]. 17 ํ. Encontro Nacional de Pesquisadores em Jornalismo, Goiânia, GO, Brasil. https://bit.ly/3t4wPkE 
Bardin, L. (2016). Análise de conteúdo. Edições 70.

Bucher, T. (2012). Want to be on the top? Algorithmic power and the threat of invisibility on Facebook. New Media \& Society, 14(7), 1164-1180. https://doi. org/10.1177/1461444812440159

Camargo, B. V., \& Justo, A. M. (2013). Tutorial para uso do software de análise textual IRAMUTEQ. Iramuteq. http://www.iramuteq.org/documentation/fichiers/ tutoriel-en-portugais

Carreira, K., \& Squirra, S. (2017). Automated journalism, natural language generation and the logic of good enough. Revista Observatório, 3(3), 60-84.

Cervi, E. U. (2018, outubro). Análise de conteúdo automatizada para conversações em redes sociais online: Uma proposta metodológica. [Apresentação de trabalho]. $42^{\circ}$ Encontro Anual da Anpocs, Caxambu, MG, Brasil. https://bit.ly/3EVc1OM

Christofoletti, R. (2019). A crise do jornalismo tem solução? Estação das Letras e Cores.

DalBen, S., \& D’Andréa, C. (2017, junho). Cartografando o Jornalismo Automatizado: redes sociotécnicas e incertezas na redação de notícias por robôs. [Apresentação de trabalho]. V Seminário de Pesquisa em Jornalismo Investigativo, on-line. https://bit.ly/3zNwT9J

Diakopoulos, N. (2019). Automating the news: How algorithms are rewriting the media. Harvard University Press.

Dicas do NICAR 2018 - as máquinas que fazem jornalismo e anti-jornalismo. (2021). Abraji. https://bit.ly/3F6Ffdn

Fiebig, M. F., \& Quadros, C. I. (2020, novembro). Repórter-robô: Entre conceitos e práticas do jornalismo. [Apresentação de trabalho]. 18을 Encontro Nacional de Pesquisadores em Jornalismo, online. https://bit.ly/32OUzyz

Franciscato, C. E. (2003). A atualidade do jornalismo: Bases para sua delimitação teórica. [Tese de Doutorado, Universidade Federal da Bahia]. Repositório Institucional UFBA. http://repositorio.ufba.br/ri/handle/ri/6056

Gillespie, T., Boczkowski, P. J., \& Foot, K. A. (Eds.). (2014). Media technologies: Essays on communication, materiality, and society. MIT Press.

Ioscote, F. C. (2020). Jornalismo e inteligência artificial: O estado da arte nos congressos brasileiros de comunicação entre 2010 e 2019. [Apresentação de trabalho]. 18ㅇ Encontro Nacional de Pesquisadores em Jornalismo, on-line. https://bit.ly/3G68puO

Kaufman, D. (2018). Deep learning: A inteligência artificial que domina a vida do século XXI. Teccogs: Revista Digital de Tecnologias Cognitivas, 17, 17-30.

Latar, N. L. (2018). Robot journalism: Can human journalism survive? World Scientific.

Lima Junior, W. T. (2011). Jornalismo computacional em função da "era do big data". Libero, 14(28), 45-52.

Lima Junior, W. T. (2019). Nova relação entre ser humano e máquina computacional: ambiente comunicacional baseado em interação simbiótica com a informação. Organicom, 16(31), 134-144. https://doi.org/10.11606/issn.2238-2593. organicom.2019.161412

Lima, M. R., \& Caetano, K. E. (2015). Implicações epistemológicas da pesquisa sobre novas práticas jornalísticas: Por onde começar? Revista FAMECOS, 22(3), 61-76. http://dx.doi.org/10.15448/1980-3729.2015.3.19898 
Linden, C. (2018). Algoritmos para jornalismo: O futuro da produção de notícias. Líbero, 21(41), 5-27.

Manovich, L. (2012). El software toma el mando. UOC.

Marchand, P., \& Ratinaud, P. (2012). L'analyse de similitude appliquée aux corpus textuels : Les primaires socialistes pour l'élection présidentielle française (septembreoctobre 2011). [Apresentação de trabalho]. 11o Journées Internationales d'Analyse statistique des Données Textuelles, Liège, Belgique.

Marcondes Filho, C. (2009). Ser jornalista: O desafio das tecnologias e o fim das ilusões. Paulus.

Marconi, F. (2020). Newsmakers: Artificial intelligence and the future of journalism. Columbia University Press.

Martin, K. (2019). Ethical implications and accountability of algorithms. Journal of Bussiness Ethics, 160(4), 835-850. https://doi.org/10.1007/s10551-018-3921-3

Mersch, D. (2019). Ideen zu einer kritik ,algorithmischer' Rationalität. Deutsche Zeitschrift für Philosophie, 67(5), 851-873. https://doi.org/10.1515/dzph-2019-0062

Micklethwait, J. [Global Editors Network]. (2019, 14 de junho). GEN Summit 2019: Keynote session with John Micklethwait, editor-in-chief, Bloomberg [Vídeo]. YouTube. https://www.youtube.com/watch?v=mu5BsrJINS8

Napoli, P. M. (2014). Automated media: An institutional theory perspective on algorithmic media production and consumption. Communication Theory, $24(3), 340-360$.

Newman, N., Fletcher, R., Kalogeropoulos, A., Levy, D., \& Nielsen, R. K. (2017). Reuters institute digital news report 2017. Reuters Institute; University of Oxford.

Poell, T., Nieborg, D., \& van Dijck, J. (2020). Plataformização. Fronteiras - estudos midiáticos, 22(1), 2-10. https://doi.org/10.4013/fem.2020.221.01

Quadros, C. I. (2005). Base de dados: A memória extensiva do jornalismo. Em Questão, 11(2), 409-423.

Quadros, C. I., Mielkniczuk, L., \& Barbosa, S. (2006). A study on digital journalism in Brazil. Brazilian Journalism Research, 2(2), 133-152.

Rubio, L. M., \& Ruiz, M. J. (2021). Artificial intelligence and journalism: Systematic review of scientific production in Web of Science and Scopus (2008-2019). Communication \& Society, 34(2), 159-176.

Sadin, É. (2015). La vie algorithmique : Critique de la raison numérique. L’Échappée.

Salaverría, R. (2019). Digital journalism: 25 years of research. Review article. El profesional de la información, 28(1), Artigo e280101. https://doi.org/10.3145/ epi.2019.ene.01

Santos, M. C. (2016). Narrativas automatizadas e a geração de textos jornalísticos: A estrutura de organização do lead traduzida em código. Brazilian Journalism Research, 12(1), 160-185. https://doi.org/10.25200/BJR.v12n1.2016.757

Träsel, M. (2014). Jornalismo guiado por dados: Aproximações entre a identidade jornalística e a cultura hacker. Estudos em jornalismo e mídia, 11(1), 291-304. https://doi.org/10.5007/1984-6924.2014v11n1p291

van Dijck, J. (2014). Datafication, dataism and dataveillance: Big data between scientific paradigm and ideology. Surveillance \& Society, 12(2), 197-208. 
What is the Quakebot and how does it work? $(2019,24$ de maio). Los Angeles Times. https://www.latimes.com/la-me-quakebot-faq-20190517-story.html

Winques, K. (2020). Mediações algorítmicas e espiral do silêncio: As dimensões estruturantes igreja e sindicato na recepção de conteúdos noticiosos em plataformas digitais. [Tese de doutorado, Universidade Federal de Santa Catarina]. Repositório Institucional UFSC. https://repositorio.ufsc.br/handle/123456789/216018 